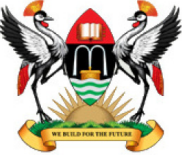

East African School of

Higher Education Studies \& Development
Makerere Journal of Higher Education

ISSN: 1816-6822; 4(2) (2013) $169-185$

DOI: http://dx.doi.org/10.4314/majohe.v4i2.4

(C) The Author(s) 2013

Reprints \& permission: EASHESD

http://ajol.info/majohe

\title{
Sampling in Qualitative Research: Improving the Quality of Research Outcomes in Higher Education
}

\author{
Julius Omona $^{1}$ \\ ${ }^{1}$ Department of Social Work and Social Administration, Makerere University [E-mail: \\ omonaju@ss.mak.ac.ug]
}

\begin{abstract}
Sampling consideration in qualitative research is very important, yet in practice this appears not to be given the prominence and the rigour it deserves among Higher Education researchers. Accordingly, the quality of research outcomes in Higher Education has suffered from low utilisation. This has motivated the production of this paper with a view to advocating for sampling so that sample size selection and sampling designs are made very crucial considerations in research designs. The paper is a desk review and predominantly used the materials from credible and authoritative sources on qualitative research. The key issues that emerged are that sample size selection and sampling designs are very important considerations for Higher Education researcher if they are interested in improving the quality of research outcomes. Importantly, there are many designs at the disposal of qualitative researchers, which are hitherto not applied. Both practitioners and those in the academia should continue emphasising the use of sampling in qualitative as in mixed and quantitative methods.
\end{abstract}

Keywords: Qualitative research; Sampling; Research methodology.

\section{$1 \quad$ Introduction}

Sampling, which basically consist of sample size and sampling designs considerations, is very important in all qualitative research. Such considerations would help qualitative researchers to select sample sizes and sample designs that are most compatible with their research purposes (Onwuegbuzie \& Leech, 2007). Sampling itself is a term that transcends research in general and research paradigms in particular. Unfortunately, sampling has not been given prominence in qualitative research. Yet, as noted by Onwuegbuzie (2003), qualitative researchers make inferences from the sample of words to each 
respondent's truth space when conducting thematic analyses on data from interviews and focus group discussions. Onwuegbuzie \& Leech (2007) contend that, in the first place, if the sample of words collected is not representative of each respondent's total truth space, then the sampling error associated with the researcher generalising the sample of words will be large. Second, in situations where the purpose of the qualitative study is to generalise the findings, both the size of the sample and the sampling design used clearly are crucial. Accordingly, sampling should be a consideration in all qualitative inquiries, regardless of purpose of research. Interestingly, this is not often the case; sample sizes are often selected in a seemingly arbitrary manner in many research studies and little or no rationale is provided for the sampling design used (Onwuegbuzie \& Leech, Ibid.).

The purpose of the present paper is firstly to advocate the use of rigour in sample size selection and designs in qualitative research in higher education to improve on the quality of research outcomes. Rigour is emphasised in research because it generally determines the validity of the research done, reliability of data generated, the extent to which results are representative, and the subjectivity of research (Namanji and Ssekyewa, 2012). According to the researcher's experience in the academia, sampling consideration in qualitative research is not given the prominence it deserves, compared to the other methods, thus leading to poor quality research outcomes and low utility. When research outcomes are of high quality, this will impact on all the stakeholders and the attendant activities and increase on the utility of the inquiry. Secondly, to emphasise the fact that sample size and designs in qualitative research are as important as they are in quantitative and mixed methods. This is a desk review and predominantly used the materials and knowledge obtained during the Workshop on research methods organised by OSSREA in Dar es Salaam from 17-22 September, 2012, which the author attended. Qualitative method is an area of special emphasis because it brings in qualities such as warmth, involvement, compassion humanism and commitment (Rubin \& Babbie, 2001) that may be lacking in the other methods.

\section{Qualitative Research and its Importance}

Before we turn to look into sample size and sampling designs, we need to explore what qualitative research is and its importance.

\subsection{What is Qualitative Research?}

Qualitative researchers believe that humans are complex, somewhat unpredictable beings and those individual differences and idiosyncratic needs 
override any notion of universal laws of human behaviours. The role of research is seen to be the deep understanding of human behaviour. Qualitative research reveals people's values, interpretative schemes, mind maps, belief systems and rules of living so that respondent's reality can be understood (Cavana, et al., 2001). Rather than concerning itself with representative sample, qualitative research emphasises careful and detailed descriptions of social practices in an attempt to understand how participants experience and explain their own world (Jackson, 1995). It is a constructivism type of research which emphasises that knowledge is active and creative (Namanji and Ssekyewa, 2012). While quantitative research is predominantly based on deductive reasoning, qualitative research involves inductive reasoning (Cavana, et al., 2001).

Some common terminologies of qualitative inquiry are phenomenology, interpretivism, hermeneutics, ethnography and grounded theory (Rubin \& Babbie, 2001). Phenomenology is a philosophical term that refers to consideration of all perceived phenomenon, both the objective and subjective. Literally, it is the study of "phenomena": appearance of things, or things as they appear in our experience, or the ways we experience things, thus the meanings things have in our experience. Qualitative researchers often attempt to make comprehensive observations at the onset and then attempt to winnow out any elements that originated in their own world view rather than in the world view of people being observed or interviewed. The aim, for instance, is to discover the subject's experiences and how they make sense of those experiences. Akin to phenomenology, interpretivism (also known as antipositism) aims at discovering how the subject of study understands his or her life. Questions such as "have you experienced discrimination by being a homosexual? Can you say something about that experience?" are all interpretivist approaches. Interpretivism holds that researchers should focus on understanding the interpretations that social actions have for the people being studied. Hermeneutics on the other hand is the study of the theory and practice of interpretations-process of understanding of social life. It aims at understanding the process of understanding. Whereas the intrepretivist seek to discover how the subject interprets his or her experience of life, the hermeneuticist is more interested in the interpretivist's process of discovery. Ethnography typically refers to naturalistic observations and holistic understanding of cultures or subcultures. For example, you may learn to see the culture of street people or the homeless poor from the perspective of the people who inhabit that culture. Grounded theory is a methodological approach that begins with observations and looks for patterns, themes, or common categories. Although it is mostly concerned with a more inductive approach to understanding, it can also incorporate deductive processes. It does this through the process of constant 
comparisons. The analysis in a grounded theory is not set up to confirm or disconfirm specific hypotheses (Rubin \& Babbie, 2001).

There are many assumptions about qualitative research and Maykut and Morehouse (1994) and Cavana, et al., 2001), identify several important parameters on which qualitative research differs from the traditional positivist assumptions thus;

a) Qualitative research places emphasis on understanding through closely examining people's words, actions and records rather than assigning mathematical symbols to these words, actions and records.

b) Rather than an objective stance, qualitative research takes a perpectival view. Qualitative research believes that meaning is co-constituted i.e. reality is socially and subjectively constructed than objectively determined (Ticehurst \&Veal, 1999). Therefore, qualitative research is interested in the subjective and perception of the respondent-that is, in examining the perspective in the respondent's beliefs and interpretation of the phenomenon being research.

c) The goal of qualitative research is to discover the patterns that emerge after close observation, careful documentation and thoughtful analysis. Until these patterns are identified, the quantitative proof of the casual nature of the variables cannot be investigated.

d) Qualitative research assumes the posture of indwelling by being at one with the person under investigation and by understanding the respondent's point of view from an emphatic rather than sympathetic position. Indwelling also involves reflection i.e., pausing to think and process what has gone before.

e) Polanyi (1997) has differentiated between tacit knowledge and explicit knowledge. Tacit knowledge is defined by saying "We know more than we can tell" (p.136), while explicit knowledge is that knowledge an individual can readily articulate. While quantitative research can access explicit knowledge, the qualitative researcher, by her or his unique combination of position and human ability, is the best instrument to surface the hidden tacit knowledge of the respondent.

f) Qualitative research looks to the human-as-an instrument for the collection and analysis of data. Only a human can be responsive, adaptable and holistic so as to explore the atypical or idiosyncratic responses that surface during an interaction with a respondent. As a human-as-an-instrument, the researcher intervenes through speech and actions to understand the "web of meaning" the respondent attributes to the phenomenon under investigation. 
It can be concluded that qualitative research tends to concentrate on collecting of great deal of rich information from relatively few people, and recognises a more fluid and recursive relationship of the various elements of the research.

\subsection{Critique and Importance of Sampling in Qualitative Research}

Many qualitative researchers contend that sample size and sample designs are not relevant in qualitative research. In quantitative research, sample size and sampling design considerations usually are made with the goal of making statistical generalisations, which involve generalising findings and inferences from representative statistical sample to the population from which the sample was drawn (Onwuegbuzie \& Leech, 2005). Conversely, because most qualitative research does not involve making statistical generalisations, many qualitative researchers state that sample size and sampling designs are not issues in qualitative research (Onwuegbuzie \& Leech, ibid.). Accordingly, very few information is available on sample size and sampling designs in qualitative research except for the work of Crowley (1995); Jones (2002); Merriam (1995), Sandelowski (1995), and lately Onwuegbuzie \& Leech, (2004, 2005 \& 2007), Collins, Onwuegbuzie, and Jiao (2006, 2007) and Teddlie and Yu (2007). Therefore, it is evident that the concepts of sample size and sampling designs have not gained much recognition among qualitative researchers. Several reasons have been advanced by these proponents that sampling designs and sample size considerations are not relevant in qualitative research.

Most importantly, some researchers associate sampling designs and/sample size considerations with an obsession with positivism, which virtually all qualitative researchers reject (Lincoln \& Guba, 2000; Schwandt, 2000). Yet rejecting positivism should not lead qualitative researchers automatically to reject considerations, such as sampling, that are made by quantitative researchers. Another reason advanced for downplaying the importance of making sample size and sampling considerations is that they represent "methodolatry", which refers to having "a preoccupation with selecting and defending methods to the exclusion of the actual story being told (Janesick, 2000, p.390). However, it can be argued that providing information to readers about sample size and sampling designs adds more richness to the story telling. Moreover, because qualitative researchers typically are not interested in making generalisations to underlying populations, it is not unusual for qualitative researchers to conclude that sampling is not an issue. Yet sampling also is important in interpretative research because many qualitative studies, if not most, involve making generalisations. Specifically, qualitative researchers tend to make analytic generalisations (Miles \&Huberman, 1994) which are "applied to wider theory on the basis of how selected cases fit with general constructs" (Curtis et al., 2000, p.1002). In order for analytical generalisations to be richer, 
the qualitative researcher should collect data that reaches data saturation (Flick, 1998; Morse, 1995), theoretical saturation (Strauss \&Cobin, 1990), or informational redundancy (Lincoln \& Guba, 1995). In support of the above, Stake (2000) noted that in "intrinsic case study, researchers do not avoid generalisations. They generalise to happenings of their cases at times yet to come and in other situations" (p.439). All these suggest that sampling considerations always are pertinent in qualitative research.

Another importance of sampling designs and sample size and usually ignored is that these are multidimensional (Onwuegbuzie \& Leech, 2005). Not only do they pertain to cases, but they also pertain to units of data (e.g. interview data, observational data). Thus for instance, a one hour interview will yield different amounts of quality of data, and, in turn, should extract more meaning than will a one-minute interview. Therefore one would expect that a longer interview would be more appropriate if a researcher was interested in a person's life history, than if the researcher was interested in the person's account of specific event. Therefore, qualitative researchers should make sampling decisions such as how many interviews or focus groups to conduct, how many sets of observations to conduct, and how long each observation period should be. These decisions should be made with the goal of attaining prolonged engagement and persistent observations (Lincoln \& Guba, 1985). Prolonged engagement and persistent observations represent sampling concepts. If not enough observational units or textual units are sampled, the quality of data will be affected and data will not be sufficiently rich and thick, making it more difficult to find meaning (Onwuegbuzie \& Leech, 2005).

While quantitative researchers use complex mathematical formulae to make sample size considerations, and they promote the use of random sampling, the sample size considerations in qualitative studies are neither mathematical nor systematic. Rather, they involve making series of decisions not only about how many individuals to include in a study and how to select these individuals, but also about the conditions under which this selection will take place. These decisions are extremely important (Curtis et al., 2000). Sampling is also important to confront the crisis of representation (Denzin \& Lincoln, 2005). The crisis of representation refers to the difficulty for qualitative researchers in adequately capturing lived experiences. Poor representation means that the researcher has not adequately captured the data (Onwuegbuzie \& Leech, 2004; Onwuegbuzie \& Frels, 2012). A good sample size and design must mitigate this crisis.

It can be concluded that within a particular qualitative study, sampling often may represent an iterative process, as is particularly the case in grounded and ethnographic studies. Choosing a sample size and sampling design should represent an active process of reflection that is based on many factors, including the context, method of collecting data, and type of generalisation needed. Thus 
sampling is a concept that transcends research studies in general and research paradigms in particular (Onwuegbuzie \& Leech, 2005). Sample size and sampling design considerations should therefore be an integral part of the qualitative research process among Higher Education researchers.

\section{$3 \quad$ Sample Size Selection Guidelines}

Although there is little consensus about what qualitative research is and how it should be undertaken (Schwandt, 2000; Sandelowski \& Barroso, 2003), there is general agreement that the goal of qualitative research is not to generalise beyond a sample to the population. Yet some qualitative researchers find it difficult to resist the temptation to generalise findings to some population (Onwuegbuzie \& Leech 2005). Such practices are flawed unless a representative sample has been selected.

The lack of sample size consideration in qualitative research likely stems from the scant discussion in this area (Onwuegbuzie \& Leech, 2007). In general the sample sizes in qualitative research should not be too small that it is difficult to achieve saturation. At the same time, the sample should not be too large that it is difficult to make deep, case-oriented analysis (Sandelowski, 1995). Qualitative research can however utilize large sample, as in case of program evaluation research. Moreover, to associate qualitative data analyses with small sample is to ignore the growing body of literature in the area of text mining-the process of analyzing naturally occurring text in order to discover and capture semantic information (cf: Del Rio et al., 2002; Liddy, 2000; Powis \&Cairns, 2003; Srinivasan, 2004; Onwuegbuzie, \& Frels, 2012).

More specifically, Creswell (2002) has recommended that qualitative researchers should, (a) study one cultural-sharing group in ethnography, (b) examine three to five cases in a case study, (c) Interview 15-20 people during a grounded theory study (d) explore the narrative stories of one individual in narrative research. In addition, Creswell (1998) recommended interviews with up to 10 people in phenomenological research and interviews with 20-30 people in grounded theory. Johnson \& Christensen (2004) surmise that focus groups usually contain 6-12 persons, whereas Langford et al., (2002) and Morgan (1997) recommends 6-10 individuals. Krueger (2000) recommends 6-9 focus group members and groups with more than 12 participants tend to "limit each person's opportunity to share insights and observations" (p.78). Furthermore, Morgan contends that focus groups with less than 6 participants make it difficult to sustain a discussion, whereas groups containing more than 12 members make it difficult for a moderator to manage the discussion. According to Kruger, focus groups must be small enough for everyone to have 
their voices represented but yet large enough to capture a range of voices. Morgan also states that 3-5 focus groups typically are sufficient to reach saturation. Kuzel (1992) recommends that 6-8 data sources or sampling units often will be sufficient when homogeneous samples are selected in qualitative research and that 12-20 data sources generally are necessary. Morse (1994) suggests that qualitative researchers use at least six participants in investigations where the goal is to understand the essence of experience. Morse also recommends 30-50 interviews and/or observations for ethnographies and grounded theory research, and approximately 100-200 units of observation in qualitative ethnographical studies. Although these guidelines are helpful, the authors did not state how they arrived at these estimates. Thus the metasummaries and metasyntheses are needed to gather evident-based data regarding suitable sample sizes. Such data should help guide qualitative researchers to establish minimum sample sizes based on the number of participants needed (Onwuegbuzie \& Leech, 2005). Furthermore, sample size selection involves more than the number of participants included in the study; it is a process that incorporates the number of participants, the number of contacts with each person, and the length of the contact. Thus, it is important when considering sampling in Higher Educational research that these issues are considered.

\section{$4 \quad$ Qualitative Sampling Designs}

Before delving into the specifics of the sampling designs (other authors variously call them techniques, approaches, strategies, schemes- cf: Rubin \& Babbie, 2001; Onwuegbuzie \& Leech, 2005; Mugenda \& Mugenda, 2003); it is important to provide the typology of sampling designs for qualitative researchers. The typology is based on their used in comparing data and these are:

(a) Parallel sampling designs, which represent a body of sampling designs that facilitate credible comparisons of two or more different subgroups that are extracted from the same level of study. These designs can involve comparing each case to all others in the sample (i.e., pair wise sampling designs) or it can involve comparing subgroups of case (i.e. sub-group sampling designs). Pairwise sampling designs traditionally have been the most common types of qualitative sampling designs. They are called "pairwise" because all the selected case are treated as a set and their voice is compared to all other cases one at a time in order to understand better the underlying phenomenon, assuming that the collective voices generated by the set of cases lead to data saturation (Onwuegbuzie \& Leech, 2007). In contrast to pair wise sampling designs, 
subgroup designs involve the comparisons of different subgroups (e.g. girls vs. boys) that are extracted from the same level of study (e.g. third year University students) and their voices are compared. The table below shows the example of a research on third year students on the same course involving different nationalities (Sub-groups).

Table 1: Example of Gender x Nationality subgroup sampling design ${ }^{\text {a }}$

\begin{tabular}{llllll}
\hline Gender & Ugandan & Kenyan & Tanzanian & Rwandese & Total \\
\hline Female & $n 4$ & $n 4$ & $n 4$ & $n 4$ & $n 16$ \\
Male & $n 4$ & $n 4$ & $n 4$ & $n 4$ & $n 16$ \\
Total & $n 8$ & $n 8$ & $n 8$ & $n 8$ & $N 32$ \\
\hline
\end{tabular}

${ }^{\mathrm{a}}$ This is a $2 \mathrm{x} 4$ subgroup sampling design.

Source: Author

(b) Nested sampling designs, are sampling designs that facilitate credible comparisons of two or more members of the same subgroup, wherein one or more members of the sub-group represent a sub-sample of the full sample. The goal of this sub-sampling is to obtain a sub-sample of cases from which further data can be extracted. This sub-sampling often takes the form of theoretical sampling, which involves the sampling of additional people, incidents, events, activities, documents and the like in order to develop emergent themes; to assess the adequacy, relevance, and meaningfulness of themes; to refine ideas; and to identify conceptual boundaries (Charmaz, 2000). According to Charmaz, (Ibid.), the aim of theoretical sampling is to refine ideas, not to increase the size of the original sample. Because theoretical sampling is the hallmark of grounded theory designs (Glaser \& Strauss, 1967), nested sampling designs are particularly pertinent for grounded theories. Nested sampling designs are most commonly used to select key informants as well as conducting member checks on a sub-sample of the study participants. Findings from key informants are generalised to the other non-informant sample members. Random sampling might be appropriate for nested sampling designs. In addition, the following purposive sampling designs are applicable in nested sampling: maximum variation, critical case sampling, theory-based sampling, typical case sampling, random purposeful sampling, multi-stage purposeful random sampling and multi-stage purposeful sampling (Onwuegbuzie \& Collins, 2007).

c) Multilevel sampling designs represent sampling designs that facilitate credible comparisons of two or more sub-groups that are extracted from different levels of study (Onwuegbuzie \& Leech, 2007). For example, a qualitative researcher might be interested in comparing the perceptions of students regarding standardised tests to those of their lecturers. The student and lecturer samples represent some form of hierarchy. Because of this hierarchy, the sampling designs and sample sizes used for the lower- level and upper-level 
samples/sub-samples typically are not uniform. For example, because students represent the lower-level sample/sub-sample and their lecturer(s) represents the upper-level, the voices of several students can be compared with the voice of one lecturer. Further, whereas the student participants (lower-level sample) might be selected using any of the available sampling designs, the lecturer likely would be selected either via convenient sampling, critical case sampling, politically important case sampling, or criterion sampling, or by using one of the four random sampling designs, in situations where the researcher has a pool of teacher from which to select the upper- level sample/sub-sample (Onwuegbuzie \& Leech, 2007).

In selecting a sample size, there are many sample designs at the disposal of the researcher-both during qualitative, mixed or quantitative sample selection. Onwuegbuzie \& Leech (2005) posit that there are 24 sample designs, which fall either under the random or non-random and are the same designs that can be used for comparative purposes mentioned above, depending on the purpose of the research.

\subsection{Random (Probability Sampling)}

Before deciding on whom to select for the inquiry and how to select the sample, qualitative researchers must decide what the objective of the study is (Onwuegbuzie, et al., 2004). If the objective of the study is to generalise the interpretations to a population, then the researcher should attempt to select a sample that is both random and large (Creswell, 2002; Johnson \& Christensen, 2004). In this situation, the qualitative researcher can select one of the five random sampling designs at a particular stage of the sampling process discussed below.

a) Simple Random Sampling. Here, respondents are selected in such a way that every person in the population has the same probability of being selected for the study, and the selection of the individual does not affect selection of any other individual (i.e. independence).

b) Stratified Random Sampling. Stratified Random sampling represents a sampling design in which a population is divided into sub-populations such that members of each sub-population are relatively homogeneous with respect to one or more characteristics and relatively heterogeneous from members of all other sub-groups with respect to this/these characteristics. In order to obtain a stratified random sampling, the sampling frame is first divided into subpopulations, or strata. Next, a random sample is selected from each stratum. The goal of stratified random sampling is to select a sample in such a way that the target sub-groups are represented in the sample in the same proportion that they exist in the population. 
c) Cluster Random Sampling. This is a method of randomly selecting clusters of individuals instead of randomly selecting individuals one at a time.

d) Systematic Random Sampling. This is a sampling method in which individual are selected from a list by choosing every $k$ th sampling frame member, were $k$ represents the population size divided by the desired sample size.

e) Multi-stage Random Sampling. This involves selecting a sample in two or more stages because either the population is relatively large or its members cannot easily be identified. In multi-stage random sampling, the first stage often involves cluster sampling, whereas subsequent stages involve simple random sampling, stratified random sampling, cluster random sampling and/or systematic random sampling.

\subsection{Non-Random Sampling}

This is known by other researchers as biased sampling (Mugenda \& Mugenda, 2003) or non-probability sampling (Minichiello, et al., 1990). If the goal is not to generalise to a population but obtain insights into a phenomenon, individuals, or events, as will typically be the case in qualitative research, and then the researcher purposefully selects individuals, groups, and settings that maximise understanding of the phenomenon. As such, the most common method of sampling in qualitative research is purposeful sampling. Here, individuals, groups, and settings are considered for selection if they are "Information rich" (Patton, 1990, p.169). The following are the common designs for non-random sampling (Miles \& Huberman, 1994; Creswell, 2002). These designs differ with respect to whether they are implemented before data collection has started or after data collection has began. Also the appropriateness of each design is dependent on the research objective, purpose and question.

a) Maximum variation sampling. According to Sandelowski (1995), maximum variation sampling is one of the most frequently used purposeful sampling designs. In this method, a wide range of individuals, groups, or settings is purposively selected such that all or most types of individuals; groups or settings are selected for the inquiry. This allows for multiple perspectives of individuals to be presented that exemplify the complexity of the world (Creswell, 2002).

b) Homogenous sampling. In contrast to maximum variation sampling, homogenous sampling involves individuals, groups, or settings because they all possess similar characteristics or attributes. Participants are selected for the study based on membership in a sub-group or unit that has specific characteristics. This sampling approach often is used to select focus groups (Onwuegbuzie et al., 2004). 
c)Critical case sampling. Here, individuals, groups, or settings are selected that bring to the fore the phenomenon of interest such that the researcher can learn more about the phenomenon than would have been learned without including these critical cases.

d) Theory-based sampling. In theory based sampling, individuals, groups, or settings are selected because they help the qualitative researcher to develop a theory. This sampling scheme is also used to expand a theory.

e) Confirming and disconfirming cases sampling. This method of sampling often is used after data collection has commenced. The former (i.e., exploratory) tends to improve interpretation of the findings, whereas the latter (i.e. confirmation) tends to assist in data validation (Miles \& Huberman, 1994).

f) Snow ball sampling. This is also known as network sampling and usually come to the fore after data collection has begun. Snowball sampling involves asking participants who have already been selected for the study to recruit other participants.

g) Extreme case sampling. In extreme case sampling, an outlying case or one that possess one or more extreme characteristics is studied. The method is to select extreme cases and then to compare them. For example, in a study of performance of graduate students, a researcher can select the best and the worse students in class and compare the causes of their performances.

h) Typical case sampling. Here, the researcher studies an individual, group, or setting that is typical. The researcher should consult several experts in the field of study in order to obtain a consensus as to what example(s) is typical of the phenomenon and should, therefore, be studied (Johnson \& Christensen, 2004).

i) Intensity sampling. In intensity sampling, the researcher studies individuals, groups, or settings that experience the phenomenon intensely but not extremely.

j)Politically important sampling. Here, the researcher selects pertinent informants who may need to be included/ excluded because they connect with politically sensitive issues expected in the analysis (Miles \& Huberman, 1994).

k) Stratified purposeful sampling. This is similar to stratified random sampling. In order to obtain a stratified purposeful sample, the sampling frame is first divided into strata; then a purposeful sample is selected from each stratum. Such a sampling design can facilitate group comparisons (Miles \& Huberman, 1994).

l) Criterion Sampling. In criterion sampling, individuals, groups, or settings are selected that meet criteria. According to Miles \& Huberman (1994), this sampling technique typically is utilised for the purpose of quality assurance.

m) Opportunistic sampling. In opportunistic sampling, the researcher capitalises on opportunities during data collection stage to select cases. These cases could represent typical, negative, critical, or extreme cases (Johnson \& 
Christensen, 2004). Opportunistic sampling takes place after the study begins in order to take advantage of developing events. This form of sampling is particularly useful when the researcher is unable or unwilling to declare in advance of the inquiry every case that will be included in the investigation.

n) Mixed purposeful sampling. This method of sampling involves the mixing of more than one sampling design. For example, the researcher might begin by selecting two samples: one via extreme case sampling and the other via critical case sampling. The researcher could then compare the results emerging from both samples. Consequently, mixed purposeful sampling can help to triangulate data (Miles \& Huberman, 1994).

o) Convenience sampling. Convenience sampling is used by researchers involves in selecting individuals or groups that happen to be available and are willing to participate in the research at the time. It is also referred to as "volunteer sampling" or "accidental sampling" (Mugenda \& Mugenda, 2003). Selecting a roommate or a neighbour is an example (Mugenda \& Mugenda, Ibid.).

p) Quota sampling. In quota sampling, the researcher decides on the specific characteristics and quotas of sample members to be selected. For example, a researcher may want to include a certain religion or social class in the sample and therefore picks quotas of each (Mugenda \& Mugenda, 2003). The researcher then purposively picks subjects to fit the quotas identified. A main limitation of this method of sampling is that only those who are accessible at that time of selection have a chance of being selected.

q) Random purposive sampling. In random purposive sampling, the researcher chooses cases at random from the sampling frame consisting of a purposefully selected sample. That is, the researcher first obtains a list of individuals of interests for the study using one of the other methods of purposive sampling, and then randomly selects a desired number of individuals from the list. According to Miles \& Huberman (1994, p. 28), random purposeful sampling "adds credibility to sample when potential purposeful sample is too large".

r) Multi-stage purposeful random sampling. This involves selecting a sample in two or more stages, in which the first stage is random, and subsequent stages are purposive. In multi-stage random purposeful sampling the first stage often involves cluster sampling, whereas subsequent stages involve one of the above purposive sampling schemes outlined (Onwuegbuzie \& Leech, 2007).

s) Multi-stage purposeful sampling. Multi-stage purposeful sampling also involves selecting a sample in two or more stages. However, all stages incorporate purposive sampling, unlike the multi-stage purposeful random sampling. Multi-stage purposeful sampling is different from mixed purposeful sampling in that the former is always sequential; whereas the latter typically 
involves concurrent sampling in which one sample is not a subset of other samples (Onwuegbuzie \& Leech, 2007).

From the above, Higher Education qualitative researchers, as do quantitative researchers, have many sampling options from which to choose. As Kemper et al. (2003, p. 292) concluded, "the understanding of a wide range of sampling designs in one's methodological repertoire greatly increases the likelihood of one's generating findings that are both rich in content and inclusive in scope". Researchers in higher education will improve the quality of their finding by being knowledgeable and applying these rich options.

\section{$5 \quad$ Conclusion and Lessons for Researchers}

It can be concluded that qualitative research method, and in particular sampling is an important and key aspect of research methodology that researchers in Higher Education should embrace. Issues on sample size selection and sampling designs in Higher Education, just as in other disciplines, should be key considerations as in mixed or quantitative methods. What can be learned is that there are guidelines on sample size selection and varieties of sampling designs some of which are hardly applied by qualitative researchers. Knowledge and expertise in their application by researchers can enhance the quality and utility of Higher Educational Research outcomes. In the academia, qualitative research in general and sampling in particular should receive the emphasis it deserves in the lecture rooms.

\section{Acknowledgements}

The author wishes to acknowledge the contributions of the following two individuals in particular for helping write this paper: Anthony J. Onwuegbuzie, Professor at Sam Houston State University and Rebecca K. Frels, Assistant Professor at Lamar University. Both were resource persons during the 17-22 September OSSREA Workshop on Research Methodology in Dar es Salaam, which the author attended. They did not only provide the insights and inspiration but the relevant and authoritative reading materials on qualitative research method most of which helped in compiling this paper. The author also thanks the Editor and Reviewers of this Journal for their help in improving the quality of this paper.

\section{References}

Cavana, R. Y., Delahaye, B. L., \& Sekaran, U. (2001) Applied Business Research: Qualitative and Quantities Methods. New York: John Wiley \& Sons Australia. 
Charmaz, K. (2000). Grounded theory: Objectivist and constructivist methods. In N.K. Denzin \& Y.S. Lincoln (eds.), Handbook of qualitative research (2nd ed., pp.509-535). Thousand Oaks, CA: Sage.

Collins, K. M.T., Onwuegbuzie, A. J., \& Jiao, Q. G. (2006). Prevalence of mixed methods sampling designs in social sci3ence research. Evaluation and Research in Education, 19,83-101.

Collins, K. M.T., Onwuegbuzie, A. J., \& Jiao, Q. G. (2007). A mixed methods investigation of mixed methods sampling designs in social and health science research. Journal of Mixed Methods Research, 1, 267-294.

Creswell, J.W. (1998). Qualitative inquiry and research design: Choosing among five traditions. Thousand Oaks, CA: Sage.

Creswell, J.W. (2002). Educational Research: Planning, conducting, and evaluating qualitative and quantitative research. New Jersey: Pearson Education: Upper Saddle River.

Crowley, E.P. (1995). Using qualitative methods in special education research. Exceptionality, 5, 55-70.

Curtis, S., Gesler, W., Smith, G., \& Washburn, S. (2002). Approaches to sampling and case selection in qualitative research: Examples in the geography of health. Social Science and Medicine, 50, 1001-1014.

Del Rio, J.A., Kostoff, R.N.., Garcia, E. O., Ramirez, A. M., \& Humenik, J.A. (2002) Phenomenological approach to profile impact of scientific research: Citation mining. Advances in Complex systems, 5(1), 19-42.

Denzin, N. K., \& Lincoln, Y. S. (2005). The discipline and practice of qualitative research. In N.K. Denzin \& Y.S. Lincoln (eds.), Handbook of qualitative research ( $3^{\text {rd }}$ ed., pp.1-32). Thousand Oaks, CA: Sage.

Flick, U. (1998). An introduction to qualitative research: Theory, method, and applications. London: Sage.

Glaser, B. G., \& Strauss, A. L. (1967). The discovery of grounded theory: Strategies for qualitative research. Chicago: Aldine.

Guba, E. (1981). Criteria for assessing the trustworthiness of naturalistic inquiries. Education Communication Technology, 29(2), 75-79.

Jackson, W. (1995). Methods: Doing Social Research. Prentice Hall: Toronto.

Janesick, V.J. (2000). The choreography of qualitative research designs. In N.K. Denzin \& Y.S. Lincoln (eds.), Handbook of qualitative research ( $2^{\text {nd }}$ ed., pp.379-399). Thousand Oaks, CA: Sage.

Johnson, B. \& Christensen, L. (2004). Educational Research: Quantitative, Qualitative, and Mixed approaches ( $2^{\text {nd }}$ ed). Needham Heights, MA: Allyn \& Bacon.

Jones, S.R. (2002). Writing the word: Methodological strategies and issues in qualitative research. Journal of College Student Development, 43, 461-473.

Kemper, E. A., Stringfield, S. \& Teddlie, C. (2003). Mixed methods sampling strategies in social science research, In A. Tashakkori \& C. Teddlie (eds.) 
Handbook of Mixed Methods in Social and Behavioural Research, pp 273296. Thousand Oaks, CA: Sage.

Krueger, R.A. (2000). Focus groups: A practical guide for applied research ( $3^{\text {rd }}$ ed.). Thousand Oak, CA: Sage.

Kuzel, A. J. (1992). Sampling in qualitative inquiry. In B.F. Crabtree \& W.L. Miller (eds.), Doing qualitative research. Research Methods for Primary Care. Vol.3, 31-44. Newbury Park, CA: Sage.

Langford, B. E., Schoenfeld, G. \& Izzo, G. (2002). Nominal grouping sessions vs. focus groups. Qualitative Market Research 5: 58-70.

Liddy, E.D. (2000). Text mining. Bulletin of American Society for Information Science and Technology, 27 (1), 14-16.

Lincoln, Y. S., \& Guba, E. G.(2000). Paradigmatic controversies, contradictions, and emerging confluences. In N. K. Denzin \&Y.S. Lincoln (Eds.), Handbook of qualitative research ( $2^{\text {nd }}$ ed., pp.163-188). Thousand Oaks, CA: Sage.

Maykut, P., \& Morehouse, R. (1994). Beginning Qualitative Research: A Philosophic and Practical Guide. London: The Falmer Press.

Merriam, S.B. (1995). What can you tell from and $\mathrm{N}$ of 1: Issues of validity and reliability in qualitative research. PAACE Journal of Lifelong Learning, 4, 51-60.

Miles, M., \& Huberman, A.M. (1994). Qualitative data analysis: An expanded sourcebook $\left(2^{\text {nd }}\right.$ ed.). Thousand Oaks, CA: Sage.

Minichiello, V., Aroni, R., Timewell, E., \& Alexander, L. (1990). In-depth Interviewing: Researching People. Longman Cheshire: Melbourne.

Morgan, D. L. (1997). Focus groups as qualitative research. Qualitative Research Methods Series, 16. Thousand Oaks, CA: Sage.

Morse, J.M. (1994). Designing funded qualitative research. In N.K. Denzin \& Y.S. Lincoln (eds.), Handbook of qualitative research (pp.220-235). Thousand Oaks, CA: Sage.

Mugenda, O. M.\& Mugenda, A. G. (2003). Research Methods: Quantitative and Qualitative Approaches. Nairobi: ACTS Press.

Namanji S., \& Ssekyewa, C. (2012). Role and Nature of Research in Development. Makerere Journal of Higher Education, 4 (1) 83-92.

Onwuegbuzie, A.J. (2003). Effect sizes in qualitative research: A prolegomenon. Quality and Quantity: International Journal of Methodology, 37,393-409.

Onwuegbuzie, A.J. \& Leech, N.L. (2004).Enhancing the interpretation of "significant" findings: The role of mixed methods Research. The Qualitative Report, 9,770-792.

Onwuegbuzie, A.J. \& Leech, N.L. (2005). The role of sampling in qualitative research. Academic Exchange Quarterly-September 22. 
Onwuegbuzie, A. J. (2007). A Call for Qualitative Power Analyses. Quality \& Quantity, 41:105-121.

Onwuegbuzie, A. J. \& Collins, K. M. T. (2007). A typology of mixed methods sampling designs in social science research. The Qualitative Report, 12 (2), 281-316.

Onwuegbuzie, A. J. \& Frels, R.K. (2012). OSSREA Workshop: Refresher Course on PhD Research Methodology Training in Social Sciences and Humanities, September 17-22, Dar es Salaam.

Polanyi, M. (1997. Science, Economics and Philosophy: Selected Papers of Michael Polanyi. In R.T Allen (ed.), Essays from 1917-1972. London: Transaction Publishers.

Patton, M.Q. (1990). Qualitative Research and Education Methods (2 $2^{\text {nd }}$ ed.). Newbury Park, CA: Sage.

Powis, T., \& Cairns, D. (2003). Mining for meaning: Text mining the relationship between social representations of reconciliation and beliefs about aboriginals. Australian Journal of Psychology, 55, 59-62.

Rubin, A. \& Babbie, E. (2001). Research Methods for Social Workers (4rth Edition). Belmont, CA: Wadsworth Thomson Learning.

Sandelowski, M. (1995). Focus on quantitative methods: Sample sizes, in qualitative research. Research in Nursing and Health, 18, 179-183.

Sandelowski, M. \& Barroso, J. (2003). Classifying the findings in qualitative studies. Qualitative Health Research 13, 905-923.

Schwandt, T. A. (2000). Three epistemological stances for qualitative inquiry: Interpretivism, hermeneutics, and social constructivism. In N. K. Denzin \&Y. S. Lincoln (Eds.), Handbook of qualitative research $\left(2^{\text {nd }}\right.$ ed., pp.189213). Thousand Oaks, CA: Sage.

Srinivasan, P. (2004). Generation hypotheses from MEDLINE. Journal of the American Society for Information Science and Technology, 55, 396-413.

Stake, R. E. (2000). Case studies. In N. K. Denzin \&Y.S. Lincoln (Eds.), Handbook of qualitative research ( $2^{\text {nd }}$ ed.), pp.435-454). Thousand Oaks, CA: Sage.

Strauss, A., \& Corbin, J. (1990). Basics of qualitative research: Grounded theory procedures and techniques. Newbury Park, CA: Sage.

Teddlie, C., \& Yu, F. (2007). Mixed methods sampling: A typology with examples. Journal of Mixed Method Research, 1,77-100.

Ticehurst, G.W., \& Veal, A. J. (1999). Business Research Methods: A Managerial Approach. Sydney: Longman. 
